\title{
INTEGRATING THE OCEAN OBSERVING SYSTEM: MOBILE PLATFORMS
}

\author{
Dean Roemmich $^{(1)}$, Lars Boehme ${ }^{(2)}$, Hervé Claustre ${ }^{(3)}$, Howard Freeland ${ }^{(4)}$, Masao Fukasawa ${ }^{(5)}$, Gustavo Goni ${ }^{(6)}$, \\ W. John Gould ${ }^{(7)}$, Nicolas Gruber ${ }^{(8)}$, Maria Hood ${ }^{(9)}$, Elizabeth Kent ${ }^{(10)}$, Rick Lumpkin ${ }^{(11)}$, Shawn Smith ${ }^{(12)}$, Pierre \\ Testor ${ }^{(13)}$ \\ ${ }^{(1)}$ Scripps Institution of Oceanography, University of California San Diego, 9500 Gilman Drive, La Jolla, CA 92093- \\ 0230, USA, Email: droemmich@ucsd.edu \\ ${ }^{(2)}$ NERC Sea Mammal Research Unit, Scottish Oceans Institute, University of St Andrews, St Andrews, Fife KY16 8LB, \\ Scotland, UK, Email: lb284@st-andrews.ac.uk \\ ${ }^{(3)}$ Laboratoire d'Océanographie de Villefranche,06230 Villefranche-sur-Mer, France, Email: claustre@obs-vlfr.fr

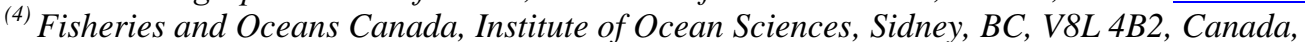 \\ Email: howard.freeland@dfo-mpo.gc.ca \\ (5) Japan Agency for Marine Science and Technology, 2-15 Natsushima, Yokosuka, Kanagawa 237-0061, Japan, \\ Email: fksw@jamstec.go.jp \\ ${ }^{(6)}$ NOAA/AOML, 4301 Rickenbacker Causeway, Miami, FL 33149, USA, Email: gustavo.goni@noaa.gov \\ (7) National Oceanography Centre, Empress Dock, Southampton, SO14 3ZH, U. K., Email: wig@@noc.soton.ac.uk \\ ${ }^{(8)}$ Institute of Biogeochemistry and Pollutant Dynamics, ETH Zurich, Universitatstrasse 16, 8092 Zurich, Switzerland, \\ Email: Nicolas.gruber@env.ethz.ch \\ (9) UNESCO-IOC, 1 Rue Miollis, 75732 Paris cedex 15, France, Email: maria.hood@ioccp.org \\ ${ }^{(10)}$ National Oceanography Centre, Empress Dock, Southampton, SO14 3ZH, U. K., Email: eck@ noc.soton.ac.uk \\ ${ }^{(11)}$ NOAA/AOML, 4301 Rickenbacker Causeway, Miami, FL 33149, USA, Email: rick.lumpkin@noaa.gov \\ ${ }^{(12)}$ Center for Ocean-Atmospheric Prediction Studies, Florida State University, 2035 E. Paul Dirac Drive, Tallahassee, \\ FL 32306-2840, USA, Email: smith@coaps.fsu.edu \\ ${ }^{(13)}$ LOCEAN-IPSL/CNRS, Université Pierre et Marie Curie, Paris, France, Email: testor@locean-ipsl.upmc.fr
}

\begin{abstract}
Potential extensions to each of the ocean observing system's mobile platform networks, made possible by new technologies, are examined with respect to the value of the complete observing system. The autonomous instrument networks now have the potential for the truly global scope that will come from extensions to high latitudes, into marginal seas and the deep ocean, and by high-resolution sampling in boundary currents. The autonomous networks can accommodate new sensors, including oxygen, chlorophyll-A, and particulate organic carbon, and coordination with shipboard and moored platform programs will enable studies of the impacts of climate variability and change on biogeochemistry and ecosystems. The systems required to observe ocean surface properties, surface circulation, and air-sea exchanges merit further study since improvements in these areas will come not only from new instrumentation but through better coordination between networks and better use of research and commercial vessels. The observing system infrastructure must evolve in parallel with the system's scope and complexity. Expanded roles are seen for smaller research vessels, including instrument deployment and recovery, reference-quality profile measurements and underway surface observations. The data management system must provide the rigorous control needed for the production of research quality datasets. The challenge in providing these enhancements to the ocean observing system is to define and achieve
\end{abstract}

an optimal mix of shipboard and autonomous observations to deliver climate-quality datasets in a cost-efficient manner that exploits the synergies between satellite and in situ observations.

\section{INTRODUCTION}

In the decade since OceanObs'99 autonomous technologies have brought about a revolution in observational capability that lets us view the subsurface oceans in ways that are comparable to global satellite measurements of the sea surface. The next decade will see equally important advances through expanded coverage and a multi-disciplinary approach. These are not expected to come from radically new technologies, but from the use and enhancement of technologies that are now maturing and from developments in existing systems. This study aims to identify the technology and infrastructure improvements most likely to advance our knowledge and understanding of climate and other application fields, both through expanding the capability of individual observing networks, and by integration across systems.

The individual networks of the present Sustained Ocean Observing System for Climate (Fig 1) including tropical moorings, XBTs (Expendable Bathythermographs), surface drifters, ship-based meteorology, tide gages, Argo (Array for Real-time Geostrophic Oceanography) floats, repeat hydrography, and satellite observations have developed largely independently of one another. 
Progress will now come from integration across the networks since the next big observational challenges including boundary currents, ice zones, the deep ocean, biological impacts of climate, and the global cycles of heat, freshwater, and carbon - demand multi-platform approaches and because exploiting the value of ocean observations is intrinsically an activity of integration and synthesis.

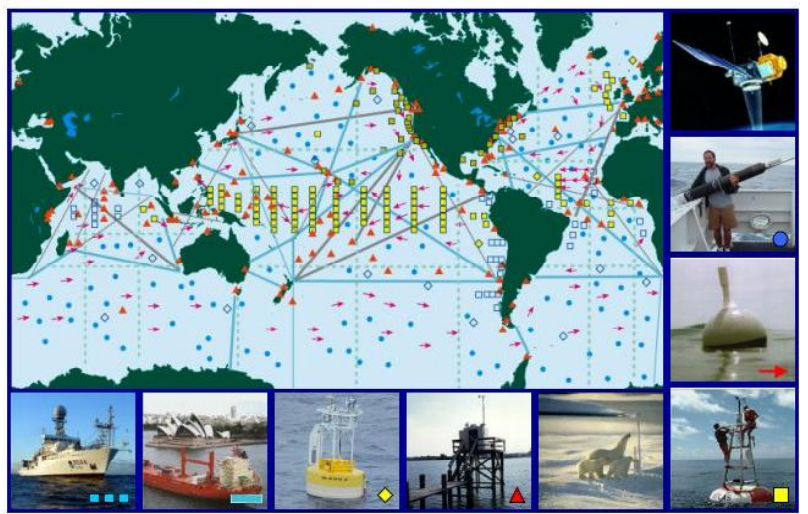

Figure 1: Schematic diagram of the Sustained Ocean Observing System for Climate.

In the past 20 years, technology developments have transformed the vision of a global ocean observing system into an operating reality. Obstacles have been overcome but many remain that will need concerted analysis and planning if they are to be surmounted. First, a global climate observing system can only be deployed as a collaborative international effort with broad participation. Climate observations are made for the benefit of all nations and people. This must be recognized and supported through (i) free and open exchange of data and data-products, (ii) international structures and agreements that enable measurements to be made without impediments, and (iii) capacitybuilding in nations needing assistance to share the benefits. Great progress has been made on the first of these issues, with free and open exchange of data gaining wide acceptance as a basic principle of the observing system. However, with a third of the deep oceans lying inside Exclusive Economic Zones, and without an international agreement on the over-riding necessity to collect and freely exchange observations globally for the common good, the observing system remains vulnerable. It should also be understood that as the knowledge of climate change is advanced, effort must be applied to investigating the impacts of these changes on society (e.g. health) and on ecosystems (fisheries, corals, etc.).

Second, for the continued development of the ocean observing system, a major limitation is the human resources needed for sustaining and improving the observational networks. The study of the ocean's role in climate has expanded rapidly as a field of research, especially in terms of the number of scientists trained to analyze and interpret ocean observations, including in models. Requirements are being established for high data quality and for extensive coverage by in situ and satellite observations to address global change issues. However, young scientists and engineers having the scientific knowledge of oceans and climate plus the specialized technical skills needed to improve ocean instruments and to design, implement, and assess observational networks are rare. It is essential to recognize and reward work in observational systems so that the stream of high quality climate data can be maintained and increased.

In the following, we identify key synergies of the observing system on which improved integration will be built (Sect. 2), and key infrastructures that will underpin an integrated global observing system (Sect. 3). Then, potential developments and improvements in the mobile platform networks are discussed, including Argo (Sect. 4), gliders (Sect. 5), repeat hydrography (Sect. 6), animal-borne sensors (Sect. 7), the Ship of Opportunity Program (SOOP) and Voluntary Observing Ship (VOS) networks (Sect. 8), automated shipboard measurements (Sect. 9), and surface drifters (Sect. 10). The largest increments to be gained over the present global observing system will come from expanding the sampling domains of autonomous platforms, from addition of multi-disciplinary measurements, and from integrating developments in data quality, coverage, and delivery.

\section{THE KEY SYNERGIES OF THE OCEAN OBSERVING SYSTEM}

What are the most important scientific relationships that bind observing system elements together and make the complete observing system greater than the sum of its parts? Understanding this question will help to prioritize possible extensions to the observing system. What additions will increase the value of the integrated system to the greatest extent?

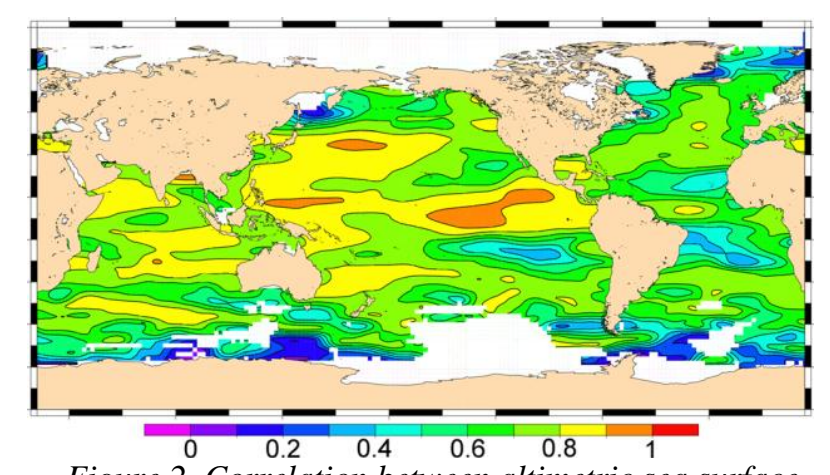

Figure 2. Correlation between altimetric sea surface height anomaly and steric height anomaly [1] 


\subsection{Argo and JASON}

On a global basis, the subsurface oceans will always be undersampled relative to their energetic spatial and temporal scales. The close dynamical relationship, and consequently high correlation, between anomalies in sea surface height and subsurface density (Fig 2) and velocity offers an opportunity to recover part of the unresolved variability in the subsurface fields using satellite altimetric height (e.g. [1] and [2]). The satellite measurements of sea surface height, together with subsurface density measurements for steric height variability, and satellite measurements of gravity, form a complete set for estimation of large-scale sea surface height variations and change (e.g. [3]). They allow us to understand sea surface height variability in terms of its underlying causes in ocean mass, density, and circulation, which will in turn permit more accurate projection of future sea level rise. The synergy of Argo and JASON will grow as the respective technologies progress, with the addition of gliders and wide-swath altimetry contributing new information on finer spatial scales. The value will also grow in proportion to the length of the time-series of high-accuracy sea surface height and global subsurface density. The combination of sea surface height with subsurface density and velocity data is a fundamental value-adding relationship in the ocean observing system, keeping in mind that the former includes both sea level gages and satellite altimetry and the latter includes floats, gliders, XBTs, repeat hydrography, moored arrays, and animal-borne profilers.

\subsection{The air-sea interface}

A second key synergistic relationship of the observing system is that linking measurements of the ocean surface layer and the overlying atmosphere [4]. Understanding the climate system requires accurate observation of the exchanges of heat, water, and momentum between the ocean and atmosphere, and hence of the properties of the ocean surface layer and lower atmosphere. Technologies to measure gas and aerosol exchanges are emerging and these exchanges are of critical interest to the climate community. The surface layer properties and exchanges are the province of many observing system elements - including profiling floats, moorings, underway ocean surface and meteorological data from research vessels and VOS, surface drifters, and satellite observations of sea surface temperature, radiation, and wind stress. One challenge is to bring together expertise from these diverse communities to set priorities and scientific goals that can help direct future sampling programs. Further combined effort by the satellite and in-situ observing communities is needed to advance air-sea flux products. Perhaps the greatest challenge in today's observing system is to improve the integration of these observational networks and the corresponding analysis tools, including data assimilation modelling, to produce accurate estimation of surface layer properties, surface circulation, and air-sea exchanges.

\section{THE SUPPORTING INFRASTRUCTURES OF THE OBSERVING SYSTEM}

Revolutionary new instruments will only fulfil their promise for global observation if there is an efficient means of getting them into and out of the ocean and an effective system for delivering their data and products to users. It is critical that the infrastructure of the observing system, including both physical and organizational elements, should evolve and be maintained in harmony with instrumental technologies and user requirements. In addition to those discussed below, other critical infrastructures of the observing system include the satellite communications systems and the international coordinating bodies.

\subsection{Access to the oceans}

Global in situ ocean observation requires regular access to all of the oceans. The development of instrumentation capable of autonomous multi-year missions fundamentally changes the requirements for access but does not eliminate them. A major factor in the success of the observing system will be the effective utilization of all available means of access to the oceans: research vessels (including both dedicated cruises and opportunistic use of transiting RVs), commercial ships, navy ships, Antarctic supply ships, and even aircraft. Improved information delivery, careful planning, and coordination are needed for this function at both national and international levels. The nascent JCOMM (Joint Technical Commission for Oceanography and Marine Meteorology) Observing Programme Support Centre (OPSC, [5]) is being developed in part for this need, but is under-resourced.

While the roles of medium-to-large research vessels are apparent and central to global observations, such as in the repeat hydrography program, the high potential value of small ocean-going RVs is only beginning to be recognized. For example, New Zealand's RV Kaharoa ( $28 \mathrm{~m}$ length, crew of 5) has deployed 750 Argo floats plus many surface drifters during nine ocean-crossing voyages since 2004 (Fig 3). Without this contribution in the remote regions of the South Pacific and Indian Oceans, where there is no commercial ship traffic and few research vessel transits, a global Argo array would not exist today and could not be maintained. In future, there are new requirements for such vessels, such as recovery of deep ocean floats or biogeochemical floats that may need sensor recalibration. These vessels can also collect high quality CTD (ConductivityTemperature-Depth) profiles to $2000 \mathrm{~m}$ depth for in situ 
float calibration, obtain ocean surface data and meteorological observations, and deploy gliders and

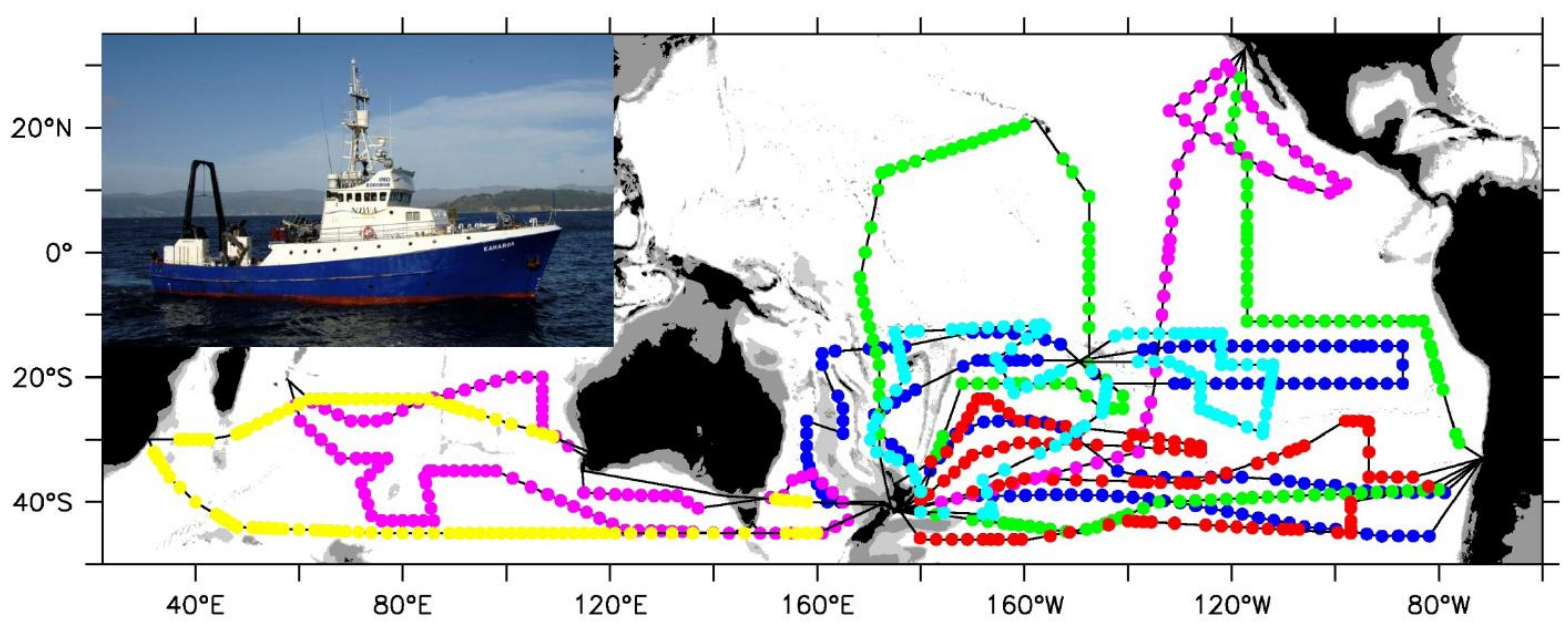

Figure 3. The Argo voyages of RV Kaharoa are shown, with different colors indicating different years. Since 2004, this small $R V$ has deployed 750 Argo floats, without which the Argo array would not have global coverage. Small RVs can perform many vital functions in global ocean observations.

\subsection{Data quality, delivery and products}

The ocean observing system is heterogeneous, and data volumes are growing rapidly year on year. For maximum value, system interoperability is required in data formats, metadata protocols, and modes of data delivery [6]. The synthesis and delivery of high-quality data and products are major undertakings that have historically been under-resourced in oceanography. Each individual component of the observing system collects data and applies quality assurance, flagging, and data adjustments before archival of data and metadata that are required for documentation and to direct steps in processing. The component observing systems each strive to maximise data quantity and quality as well as to deliver datasets as quickly and efficiently as is practical for each data type. Many of these streams include both near real-time (operational) and delayedmode (research-quality) versions. The availability of complementary observations from multiple observing systems is becoming increasingly important. For example, meteorological data are delivered from commercial ships, buoys, research vessels, marine platforms and coastal stations. Profile datasets come from profiling floats, gliders, shipboard hydrography, XBTs, moorings, and animal-borne profiles. Each data source has distinctive issues of quality and processing. There is a need for integrated datasets, unified access to distributed datasets, and archiving at world data centers to ensure long-term preservation.

There is also a need for data products, for example gridded datasets with uncertainty estimates, in addition to the observational datasets. The documentation and characterisation of products and datasets is essential along with guidance on suitability of datasets for a range of applications.

\section{EXTENDING THE ARGO PROGRAM}

Profiling floats are the only practical means at present of sampling the global subsurface oceans, and are the most cost effective platform for high quality broad-scale profile data. Hence, a basic strategy for the observing system should be to exploit float technology to the fullest extent practical through extensions of the sampling domain of the Argo Program (Global array of free-drifting profiling floats). Additional float capabilities and sensors should be added as they become ready for global deployment. The following extensions to float capabilities, Argo sampling domains, and Argo sensors are presently being tested or considered [7]. Some of these carry substantial costs and require additional resources; others are low cost and feasible at present. In addition to these potential Argo extensions, improvements in data delivery and data quality control are planned to increase Argo's value in many applications.

\subsection{High latitudes}

Strong climate signals in the high latitude oceans make a compelling case to extend Argo's domain poleward in both hemispheres, beyond the $60^{\circ} \mathrm{N} / \mathrm{S}$ specification of the initial Argo array. Float sampling under seasonal ice is now possible through ice-strengthening in some float designs and software modifications for ice avoidance in others [8]. A recommendation [9] is to extend Argo standard sampling $\left(3^{\circ} \times 3^{\circ}\right)$ poleward through the seasonal ice zones. This would require about 360 floats 
in the Southern Ocean and 285 in the Arctic seas. As of mid-2009 there are 121 active Argo floats south of $60^{\circ} \mathrm{S}$ and another 46 north of $60^{\circ} \mathrm{N}$ (Fig 4). More comprehensive rationales and prescriptions for high latitude observing systems, including floats and other autonomous platforms, are provided for the Arctic Observing Network (AON) [10] and the Southern Ocean Observing System (SOOS) [11].

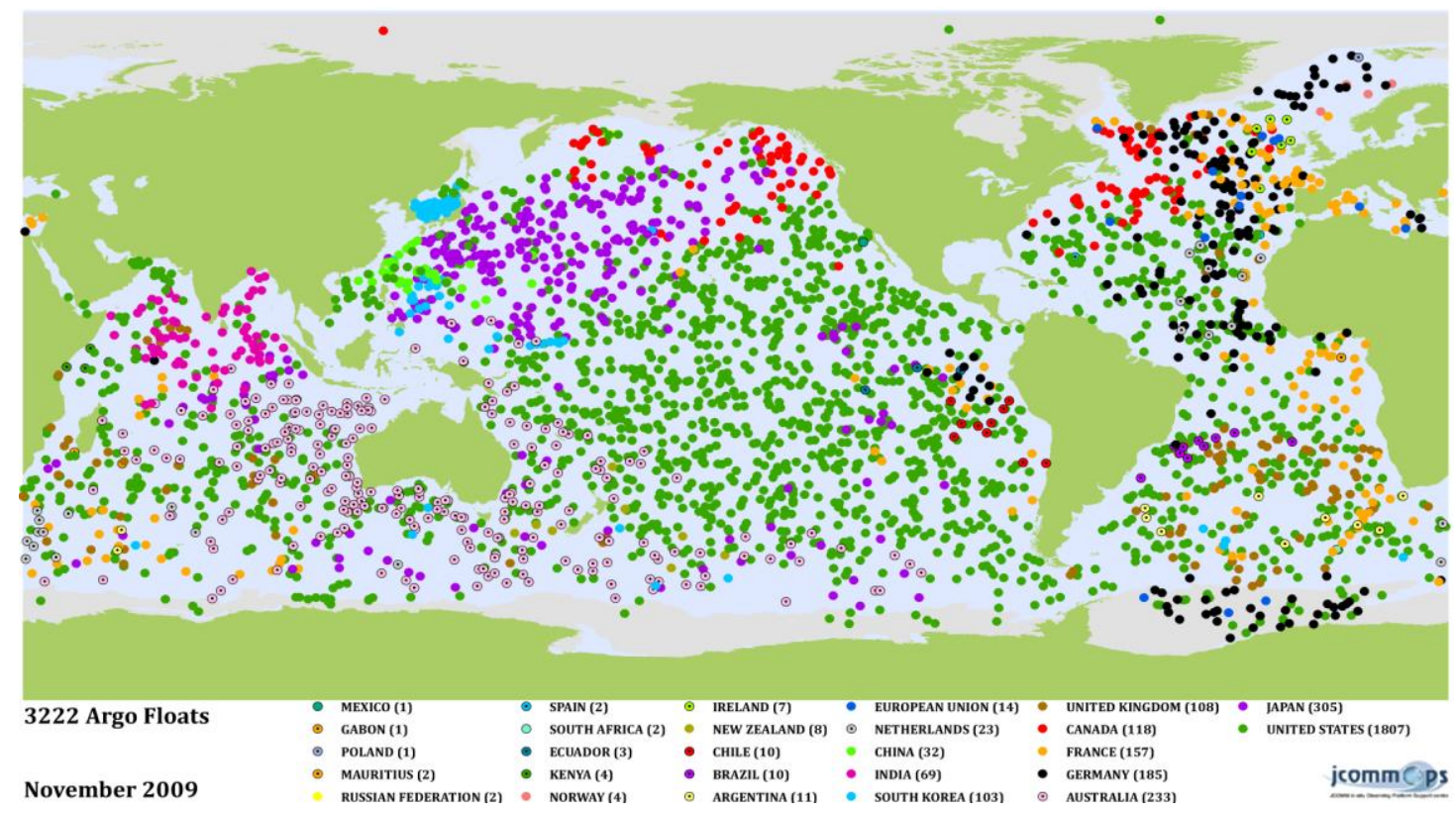

Figure 4. The present array of 3200 Argo floats could be extended in many ways to provide global climate-quality multi-disciplinary observations of the top-to-bottom oceans.

\subsection{Marginal seas}

Some marginal seas such as the Mediterranean presently have Argo coverage. Others like the Caribbean Sea and Gulf of Mexico do not, in spite of compelling scientific justification to observe upper ocean heat content in relation to tropical cyclone intensification. Float grounding problems are serious in marginal seas, but shortened float surface times made possible by bidirectional communication (Iridium and Argos-3) will provide some mitigation. Regional groups are needed to define sampling requirements for the marginal seas. Depending on these requirements, float or glider sampling or a combination of the two may prove most effective in individual cases.

\subsection{The deep ocean}

Floats capable of sampling to the ocean bottom are feasible from an engineering perspective, though more costly in materials and energy requirements than present mid-depth floats. Practical issues that will determine the achievable depth range are energy usage versus energy capacity (i.e., cycles of battery life) and recovery/recalibration capability. Climate signals in the deep ocean are small enough so that floats may need to be recovered for CTD sensor recalibration to achieve the required accuracy. The development of deep-ocean floats and of low power deep-ocean CTDs should be pursued to determine the practical limits. Requirements and technologies for a deep ocean observing system are described in [12].

\subsection{Western boundary current extension (WBCE) regions}

Argo sampling noise is a maximum at about $38^{\circ} \mathrm{N}$ and $40^{\circ} \mathrm{S}$ due to eddy variability in the $\mathrm{WBCE}$ regions. Enhanced sampling of the WBCE (Western Boundary Current Extension) regions is recommended [13] for improved accuracy in ocean data assimilation models and for studies of ventilation. Additional design studies of requirements for Argo sampling in WBCE regions are needed.

\subsection{Surface layer}

Two strategies are being tested for improved surface layer measurement in Argo. One uses a non-pumped secondary CTD having lower cost and accuracy than the primary sensor, whose pump is turned off a few meters below the air-sea interface to prevent conductivity cell contamination. In the other strategy, temperature measurements are made from the primary CTD after the pump is turned off. A decision will be needed, based on cost and accuracy requirements, whether to pursue one or both of these in large numbers of floats. 


\subsection{Active control}

Active management of the Argo array to change mission parameters underway will be possible once most of the floats are using bidirectional communications (Iridium or Argos-3). Objectives will be to increase Argo's value in a variety of applications including sampling western boundary current regions (through increased cycling frequency, or adaptive surface time or parking depth to influence location) and tropical cyclone studies (increased cycling frequency over limited depth range and seasonal changes in sampling). Active management could also be used for grounding-avoidance and iceavoidance measures where and when appropriate.

\subsection{Redundant pressure}

The most critical and limiting measurement for the profiling float CTD at present is pressure. An important lesson from Argo is that greater accuracy and reliability of individual pressure sensors or sensor redundancy is needed. The potential uses of redundant pressure sensors should be evaluated, including as a backup for failing sensors and for evaluating and improving accuracy. Minimizing systematic errors in pressure is critical for global change applications. Recovery and recalibration of a fraction of floats also would be useful.

\subsection{Miniaturization}

Since float buoyancy depends on fractional changes in volume $(\Delta \mathrm{V} / \mathrm{V})$, floats are made as small as practical to maximize their efficiency. Smaller floats now being designed and deployed require less volume change per fractional buoyancy change and therefore fewer batteries for a given number of cycles. However, since new sensors may require additional payload and energy, float designs should be scalable to maintain flexibility for different missions.

\subsection{Additional sensors- Oxygen, Chl-A, and POC}

New sensors that increase the value of the global ocean observing system are welcome additions to Argo floats. With that in mind, the international Argo program has provided guidelines for inclusion of new sensors. First, performance characteristics of the sensor, including its stability and accuracy in relation to sampling objectives, and its impact on float lifetime and performance, should be documented through deployment of demonstration arrays. Second, the added sensors must be cost-neutral with respect to the core Argo Program. That is, incremental resources are required not only for the sensors, but also to mitigate their impact on Argo. Any reduction of float lifetime would need to be offset by additional floats including deployment costs. Third, procedures for near real-time and delayed-mode processing should be developed for the new sensor, with the processing and data delivery being supported so they are again cost-neutral for the core Argo Program.

Dissolved oxygen sensors on profiling floats [14] are the most advanced with respect to the above guidelines. Oceanic dissolved oxygen is a key parameter for biological processes such as net production and for ocean geochemistry including estimated uptake of anthropogenic carbon dioxide. Advocates of oxygen measurement have worked with Argo PIs to deploy over 200 demonstration floats with oxygen sensors. Multiyear deployments are providing a wealth of information on the sensor characteristics and their scientific applications (e.g. [15]). Procedures for processing oxygen data continue in development.

Other promising sensors for large-scale deployment include fluorescence to estimate chlorophyll-A and optical backscattering to estimate particulate organic carbon (POC). The Bio-Argo group [16] recommends that $20 \%$ of the Argo array (600 floats) be equipped with Chl-A and POC sensors for objectives including the extension of satellite measurements of the sea surface into the ocean interior, validation of satellite ocean color, assimilation into future biogeochemical models, and detection of climate-related large-scale variability and trends. The addition of oxygen and biooptical sensors will require the greater communication bandwidth available with bidirectional systems.

Careful consideration will be required of procedures for delayed-mode processing to produce research quality data from additional sensors. In the case of Argo salinity sensors, multi-year drifts are adjusted by comparison with nearby high-quality data. There is less global coverage of dissolved oxygen than salinity and much less in the case of Chl-A and POC. Other means of detection and adjustment of sensor drift are needed. One possibility is recovery and recalibration. While this carries a substantial cost, we have already noted that it may be required for sufficient accuracy in deep floats.

\subsection{Ocean mixing}

Estimation of the spatial and temporal distribution of diapycnal mixing in the oceans is a critical challenge for understanding the impacts of climate variability and change, and for improvement in ocean modeling capabilities for many applications. Recent sparse measurements indicate that ocean mixing is very heterogeneous, with key issues for global observations including the vertical extent of elevated mixing over rough topography, the causes of intermittent mixing beneath the surface mixed layer, and the interactions between internal waves and eddies [17]. The addition to Argo of fine-scale measurements of density and shear could improve the global estimation of mixing through parameterization of turbulent dissipation. The most 
straightforward extension is improved vertical resolution (1-2 $\mathrm{m})$ in temperature and salinity profiles, made possible through bidirectional communication. Deeper floats (see 4.3 above) would provide more observations in the layers above rough topography, where mixing is enhanced. Finally, the addition of sensors to measure the vertical shear in horizontal velocity would be valuable, but would require a longer process to implement (sect. 4.9). The community recommendations for ocean mixing-related measurements in Argo are outlined in [17].

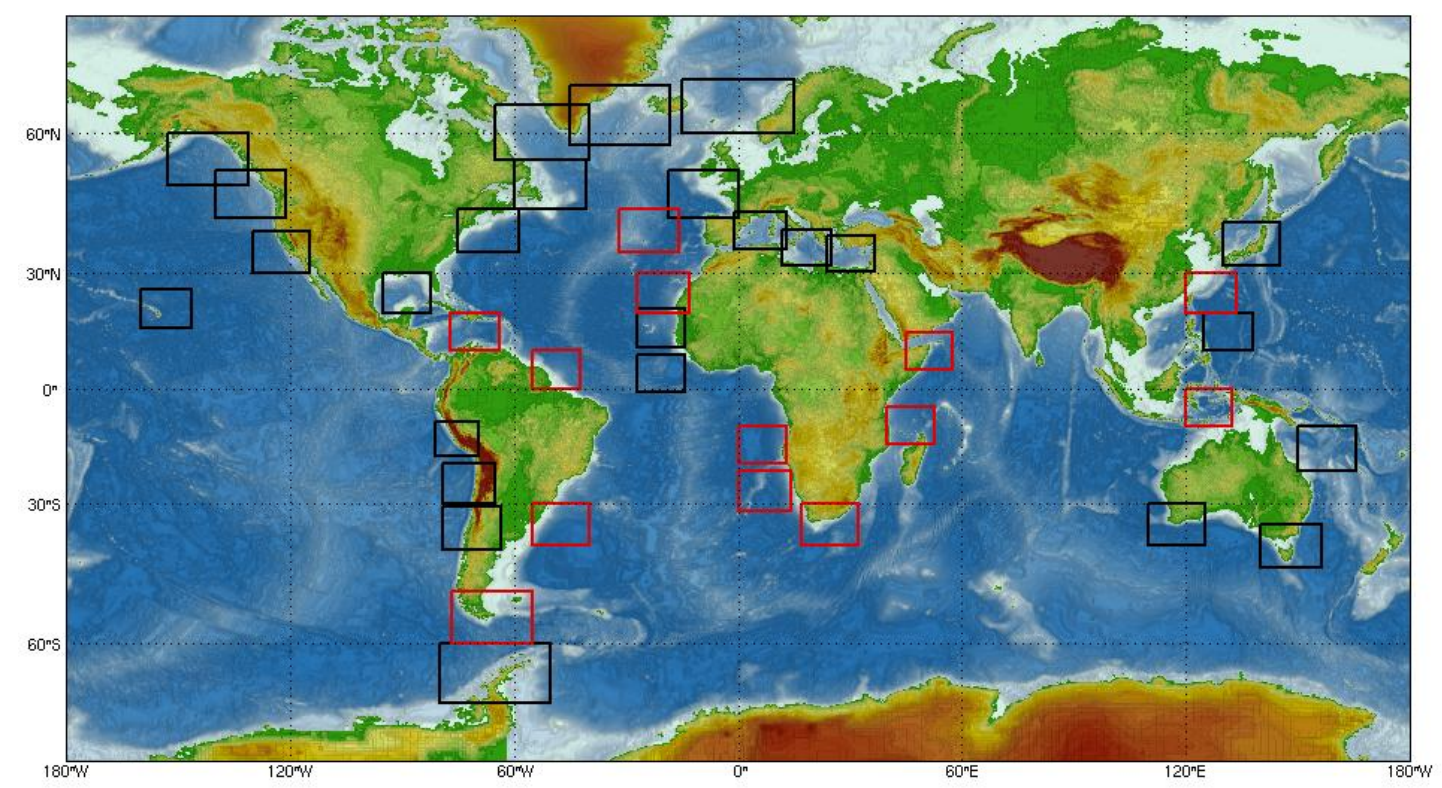

Figure 5. Map [18] of regions where gliders have been deployed (black boxes) and additional sites of interest for glider transects (red boxes).

\section{GLIDERS}

Glider technology provides the capability for sampling in regions where high spatial resolution is required, such as boundary currents, water mass formation sites, marginal seas, and straits/chokepoint sections [18]. There are presently only a few technical groups in the world capable of glider production, maintenance, and operation, and these groups are carrying out both process studies and repeating transects to demonstrate the uses of glider sampling in a variety of settings (see http://www.ego-network.org).

\subsection{Glider roles in sustained observations}

Gliders move through the water with typical horizontal speed of $25 \mathrm{~cm} / \mathrm{s}$, faster than most depth-averaged ocean currents, and therefore are able to navigate to programmed waypoints. In a single deployment they can obtain hundreds of CTD and other sensor profiles and velocity estimates, with a range of thousands of kilometers, over several months time. Because of their modest speed, glider transects deviate from their designed tracks, and the long duration means that transects are not "snapshots". These basic characteristics require gliders to be deployed in numbers sufficient for resolving the scales of interest, or deployed in combination with other measurements such as moored arrays, satellite altimetry, Argo floats, XBT transects etc.

\subsection{Prioritizing sustained glider observations}

An initial plan for sustained glider sampling in the next ten years is provided by [18] and shown schematically in Fig 5. The initial plan takes into account present glider demonstration projects, and plans by the expert glider groups. Here we ask where sustained glider deployments would add most value to the global observing system.

An important shortcoming of the present ocean observing system is the lack of systematic boundary current observations [19] and [20]. Gliders have the potential to mitigate that problem, and indeed glider sampling in boundary currents is an important element of the initial plan for glider sampling [18]. A historical record of western boundary current measurements comes from the World Ocean Circulation Experiment (WOCE), in which current meter arrays were maintained for about 2 years at $25^{\circ}-30^{\circ} \mathrm{N}$ and $30^{\circ} \mathrm{S}$ at the western boundary of all five subtropical gyres. These arrays were accompanied by trans-oceanic hydrographic transects for global estimation of meridional transports of mass, heat, and freshwater. WOCE also initiated high-resolution XBT transects, crossing boundary 
currents and ocean interiors with boundary-to-boundary sampling. Most of these transects continue, and have been used for estimation of time-varying mass and heat transports (e.g. [21] and [22]).

Because of the need for boundary current observations, the initial glider network should include transects in all the mid-latitude western boundary currents, with regionally-based planning to take advantage of historical measurements and ongoing XBT, repeat hydrography, satellite altimetry, and moored array sampling. An objective is to provide strong constraints, at one or more locations per gyre, on basin-integrated transport and hence on the global budgets of mass, heat, and freshwater. The regional perspective is essential to ensure that efficient strategies are developed to combine different measurement types for a comprehensive observing system.
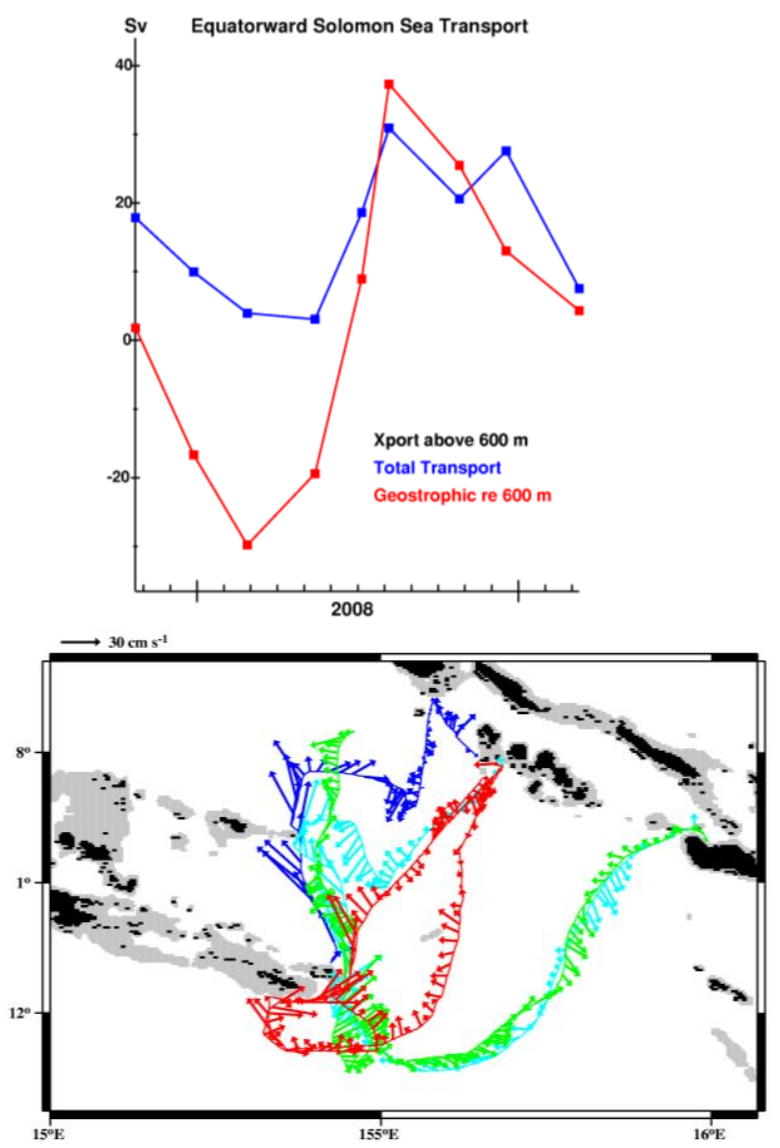

Figure 6. Glider transport time-series in the Solomon Sea, based on glider velocity (left, blue) and geostrophic velocity relative to $600 \mathrm{~m}$ (red). Glider tracks in the Solomon Sea (right). Fig from [20]

Low latitude western boundary currents (LLWBC) potentially play key roles in interannual-to-decadal climate variability, and are as important to observe as the mid-latitude ones. A demonstration project using gliders is presently being carried out in the Solomon Sea to measure the South Pacific LLWBC (Fig 6, [20]). This initial project should be sustained and replicated in other LLWBC regions, depending on feasibility. As with the mid-latitude WBCs, there needs to be a regional strategy for combining boundary current and interior transport observations for basin-integrated values.

\subsection{Floats or gliders?}

In many regions both gliders and Argo floats will be operating, and it is essential to achieve the best combination of instruments for efficient sampling. For this to happen, first the sampling requirements for sustained observation need to be established. It is generally agreed that the standard Argo coverage of $3^{\circ} \mathrm{x}$ $3^{\circ} \times 10$ days is not sufficient in some regions including boundary currents and their extensions [13] and marginal seas. Regional expertise, particularly in the case of marginal seas, is needed to define the specific objectives of sustained sampling and the sampling requirements to satisfy those objectives. The observing system can be a mixture of high-resolution transects (gliders and/or XBT) and broad-scale profiling (floats).

While the essential characteristics of gliders and floats are known, there are aspects of the technologies that are not yet understood. For example, trials are needed to establish the effectiveness of shortened surface time in floats (by means of bidirectional communication) to reduce grounding hazards. This will impact the decision to use floats or gliders in marginal seas, where float grounding is a serious problem. Similarly, it is not yet known how active management of Argo missions (variable cycle time, surface time, parking depth) can contribute to denser sampling in boundary current regions and to further reduction in grounding losses.

\subsection{The glider data stream}

Preliminary discussions have been held on integration of glider data into the Argo Data Management System, and the Coriolis Data Center now holds and distributes some glider data. Floats and gliders both produce primary datasets consisting of CTD profiles, so some aspects of combining them are straightforward. But there are also complexities. For example, glider data may need to carry horizontal location information as a function of depth while floats do not. That is, glider profiles consist of slant data while float profiles are treated as vertical. Protocols for producing research-quality data may be different for gliders and floats. Gliders have shorter missions and are recovered, making routine postmission sensor calibration possible. Finally, and perhaps most challenging, gliders may carry a greater variety of sensors than floats, and each sensor requires procedures for processing and quality-control. 


\subsection{International infrastructure}

Each element of the ocean observing system requires international coordination of design and planning, implementation, and data management. Effective tracking of the program's status is needed for coordination to occur. For a glider program, in the short term an international team should oversee the selection and prioritization of global sampling, and match these priorities with commitments by national programs to implement the global plan. Regionally specific glider strategies are needed, to either resolve scales of interest through multi-glider arrays or through combination of gliders with other observations. A data management system, built on an open data policy, and including both near real-time and delayed-mode data streams, needs to be in place from the time that major implementation of the program begins.

A unique aspect for a glider program is that gliders combine a complex and advanced technology with a substantial regional requirement for support of deployment, recovery, and instrument turnaround operations. As a consequence, new collaborations are needed between the technologically expert (in glider production and operations) groups and regional logistically capable groups in order build the capacity to deploy gliders in the regions where they are most needed. A glider program's success is likely to be defined by its ability to initiate and sustain these collaborations, which are essential for a global reach.

\section{REPEAT HYDROGRAPHY}

Shipboard hydrographic sampling is a mature element of the ocean observing system with sparse global surveys having begun in the 1970s with the Geochemical Ocean Sections Study (GEOSECS), continued into the 1990s with WOCE and, to the present with the Climate Variability and Predictability (CLIVAR) repeat hydrographic surveys. Present plans for decadal (or more frequent) repeat hydrographic transects [23] address objectives of:

- understanding the controls and distribution of carbon in the oceans,

- understanding temporal changes in the oceans below $2 \mathrm{~km}$ and their contributions to global heat and freshwater budgets

- understanding the variability in water masses, ventilation, and pathways

- quantifying transports

- $\quad$ evaluating ocean models

- $\quad$ providing a platform to test new shipboard sensors and an opportunity to deploy and evaluate other platforms.
Recognizing that the repeat hydrography program also has great stand-alone value, here we focus on aspects that bear most strongly on its integration with other observing system elements.

\subsection{Accuracy of Argo float and XBT profile data}

Shipboard hydrographic data provide the quality standard against which the data from floats and other autonomous platforms and XBTs are compared, to assess their accuracy and for detection and correction of systematic errors. The high cost of shipboard hydrography is balanced against its broad and unique capability to measure many parameters that cannot be measured by other means, and to measure those that can with highest accuracy. Cost factors limit the global hydrographic survey to less than $10^{3}$ profiles per year from the ocean surface to the bottom, while Argo floats deliver $10^{5}$ temperature/salinity profiles per year in the upper $2 \mathrm{~km}$.

Salinity drift in Argo floats is adjusted by comparison of Argo salinity to nearby high-quality salinity/temperature data [24]. In addition to salinity drift, systematic errors in float pressure measurements are also an ongoing concern (e.g. [25]). For both of these issues, the process of identifying and correcting systematic errors is dependent on, and its effectiveness is limited by, the volume and spatial distribution of recent shipboard CTD profiles. The requirements have not yet been established for high quality reference CTD data needed to validate and correct Argo. Similarly, shipboard CTD data are used to assess systematic changes over time in temperature versus depth errors from XBTs, for example to estimate and adjust the instrument's fall rate [26]. It was noted in Sect. 4 that many future Argo floats are likely to carry sensors for dissolved oxygen, chlorophyll-A, particulate organic carbon, and possibly others. All will require validation and correction through comparison to nearby shipboard data or recovery and recalibration.

\subsection{Core variables}

In order to maximize value of the observing system as a whole, it is critical for a set of core variables to be selected including some that are common to repeat hydrography and autonomous instruments - moorings, floats, and gliders. The Global Ocean Ship-based Hydrographic Investigations Panel (GO-SHIP, [23]) recommends, for example, that the profiling CTDs in the repeat hydrography program should include optical instruments for fluorescence and particulates. Thus if optical bio-sensors are added to Argo floats, the repeat hydrography survey will provide data needed for calibration and interpretation of nearby floats. Thus it also may be desirable to deploy these specialized floats 
selectively from ships doing the repeat hydrography survey.

\subsection{Repeat hydrography and deep ocean floats}

If deep ocean floats are developed and deployed in Argo, then validation and correction, requiring repeat hydrography, will be needed for those instruments as well as for the upper ocean ones. In the event that a deep float array is not deployed, then the observation of deep ocean changes in heat, freshwater, and steric sea level would rest entirely with the repeat hydrography program. Because there are gaps in the planned global sampling, of scale 5,000 km (Fig 7), errors in estimation of global integrals would be substantial. Studies are needed to assess the likely errors in global ocean heat content with and without a deep float array.

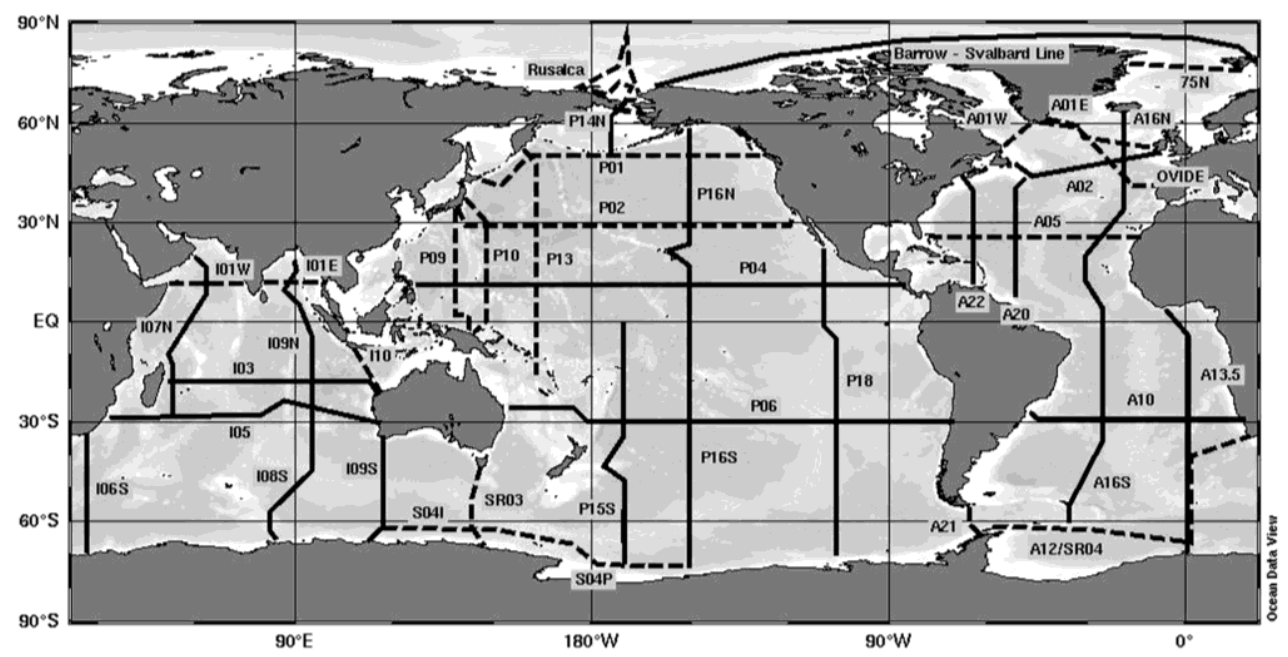

Figure 7. GO-SHIP [23] repeat hydrography plan: decadal (solid) and more frequent (dashed) lines.

\subsection{Boundary currents and interiors}

The two observing system elements that measure both the boundary current shear on fine horizontal scales and the interior ocean circulation are the repeat hydrography program (top-to-bottom, decadal repeats) and the High Resolution XBT Network (0-800 m, quarterly repeats, [27]). The repeat hydrography program includes the zonal subtropical gyre transects used in WOCE for quantifying meridional transports and overturning circulations. A recommendation is to use these transects to anchor boundary current variability studies that use gliders and other measurements [20].

\subsection{Data policy}

A recommendation of GO-SHIP [23] is to release repeat hydrography preliminary data within 6 weeks, with final physical data released within 6 months, and other data within 12 months. All national programs contributing to global ocean observations should subscribe to this policy, and invest sufficient resources in data management to provide for timely processing and distribution. It is not acceptable to delay valuable climate data from public release. These data are required for many time-sensitive applications including climate monitoring and forecast initialization, and for use in quality control of other data types.

\subsection{International Coordination}

The repeat hydrography program has evolved principally for stand-alone objectives. However, GOSHIP recognized the importance of relationships to other observing system elements, and the IOC should be encouraged, in cooperation with the global research programs, to continue a coordination activity for this network. Greater interactions between the observing system elements can be fostered in a number of ways, including greater use of the JCOMM Observations Coordination Group and the JCOMM Observing Programme Support Center. A valuable function of the JCOMM OPSC could be to track and encourage the rapid release and availability of repeat hydrography data, consistent with the data policy outlined above.

\section{ANIMAL-BORNE SENSORS}

Miniature electronic data recorders and transmitters have revolutionized the study of marine animals over the past decades. Recently, animal-borne instruments have been designed and deployed to provide in situ hydrographic data [28] and [29]. Animal-borne oceanographic instruments have enabled collection of in situ datasets with high spatial and temporal resolution even in regions that are seasonally ice-covered [30], [31], [32] and [33]. Some species are wide-ranging, while others generate quasi-Eulerian series [33] and 
[34]. Therefore, by choosing the appropriate species, animal-borne instruments can fill 'blind spots' in the sampling coverage of existing ocean observing systems.

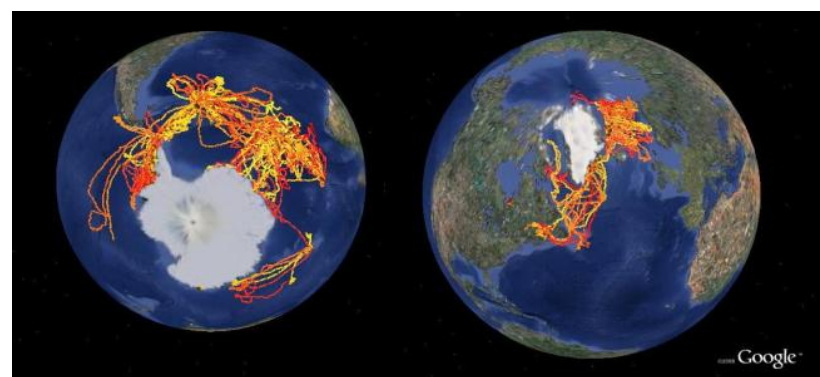

Figure 8. Partial tracks of tagged animals collected by the 'Marine Mammals Exploring the Oceans - Pole to Pole' (MEOP) project since July 2007 in polar regions.

Animal-borne instruments are proving to be sufficiently accurate to be a useful element in sustained ocean observations [29], and their natural niche is in complementary measurements of boundary currents, ocean fronts and of property fluxes across lines, as well as coverage of under-sampled ocean regions. The largest potential contribution to global ocean observations from animal-borne instruments is through enhanced coverage in the polar oceans (Fig 8). Marine mammals are typically not hampered by ice, as are Argo floats and gliders; rather they actively find breathing holes, where data are then transmitted. Time-series and sections along pack ice fronts and ice shelves, and even data from within the pack ice, far from the open ocean, provide new insights into ocean dynamics [30] and [31].

\subsection{Sampling characteristics}

Animals often traverse currents, thus providing crosscurrent vertical sections [35]. Such efforts cannot be directed as with gliders, but nonetheless can follow migration paths to provide a degree of repeatability. Animals often cross-homogeneous water masses more quickly than areas with strong horizontal gradients. This 'adaptive sampling' increases the spatial resolution in areas where it is needed.

In regions with good Argo float coverage, animal-borne instruments improve temporal resolution by providing at least daily profiles of the upper ocean along animal migrations [34]. Some animal-borne instruments can even deliver up to 6 profiles a day, depending on the instruments' configuration and available bandwidth [36]. Thus, animal-borne instruments can help to evaluate upper ocean fluxes on short timescales.

\subsection{Data system and quality control}

Data from animal-borne sensors will need to be either integrated into the Argo Data Management system or processed by a similar system yet to be established. Procedures for both real-time and delayed-mode processing are required to ensure data quality and uniformity. So far, the animal-borne instrument community has adopted real-time procedures similar to those developed by Argo. Simple quality checks are done immediately after decoding and before data are put on the Global Telecommunication System (GTS). Possible offsets resulting from different attachment methods can also be corrected at this stage [36]. When sufficient profiles are collected, delayed-mode quality control algorithms (e.g. [24]) can be used to correct other possible offsets or drifts. However, as with Argo and XBT data, final quality will depend on having sufficient nearby reference data for validation and correction of systematic errors.

\subsection{Technical development}

To increase the value of animal-borne instruments, further development work is needed on data communication and on the specialized CTDs and other new sensors. Animal-borne sensor and communication modules must be very small and light, and able to transfer profile data in the limited time an animal spends on the sea surface [36]. Present Iridium units are too large, and Argos- 2 is not optimal because of highenergy use and low bandwidth for unidirectional communication. Argos-3, with bi-directional capability, will improve on both of these aspects. Low-power CTDs have been specially developed for this application, using an inductive salinity measurement. Continued effort is needed to improve the accuracy and stability of these sensors, as well as to document their characteristics and develop procedures for delayedmode quality control.

Additional new sensors are being developed to broaden the value of animal-borne profilers within the global ocean observing system. The first deployments to estimate chlorophyll-A were successfully completed [37] and the first ready-made instruments will be available within the next year. Dissolved oxygen sensors will also be integrated into existing instruments and the first prototypes will be deployed within the next two years. 


\subsection{Ocean observations and marine mammals}

Tagging of marine mammals is acceptable only if the resulting behavioural and ecological data further the science, management and conservation of the species involved. Interdisciplinary projects are needed to understand the importance of the oceanographic environment to the reproductive success and general well-being of marine mammals. Such studies need to be longer than one reproductive cycle, and matched to the climate time-scales of the ocean. Long-term behavioural studies can be carried out, which would also deliver real-time data.

\section{THE SHIP OF OPPORTUNITY PROGRAM AND THE VOLUNTARY OBSERVING SHIP SCHEME}

The VOS [38] scheme, which is a ship-based meteorology network, and the SOOP [27], which deploys XBTs and other underway ocean measurements, are both based primarily on ocean access provided by the commercial shipping industry as well as on opportunistic use of research vessels. For this reason the two networks have many common aspects, and both are considered in this section. VOS and SOOP are mature networks with valuable historical data records. They both have challenges to adapt to the changing observing system as well as to changes in the commercial shipping industry.

The volatile nature of the commercial shipping industry in today's economy is marked by very short residence times of individual ships along most routes as well as frequent changes in the routing. This characteristic, further complicated by increased security issues, is the primary challenge for the VOS and SOOP networks. For the majority of ships, equipment installation needs to be quick and temporary; for a few ships known to have longer residence times, more labor-intensive installations are possible.

\subsection{SOOP}

XBT networks (Fig 9, red) have been used to measure upper ocean thermal variability on basin-scales for the past 30 years. These networks have made major scientific contributions to problems such as ENSO variability and the estimation of global ocean warming (e.g. [39]). They helped to provide scientific justification for the Argo Program, which has replaced the original broadscale XBT networks, and they generated statistical information used in Argo's design. The upper ocean thermal network was reviewed prior to OceanObs'99 [40], and a major evolution has taken place in the past decade [27]. Today's XBT networks, with their line-based sampling modes, are focused on temporal and spatial variability that is not resolved by the broad-scale Argo float array. For example, XBT

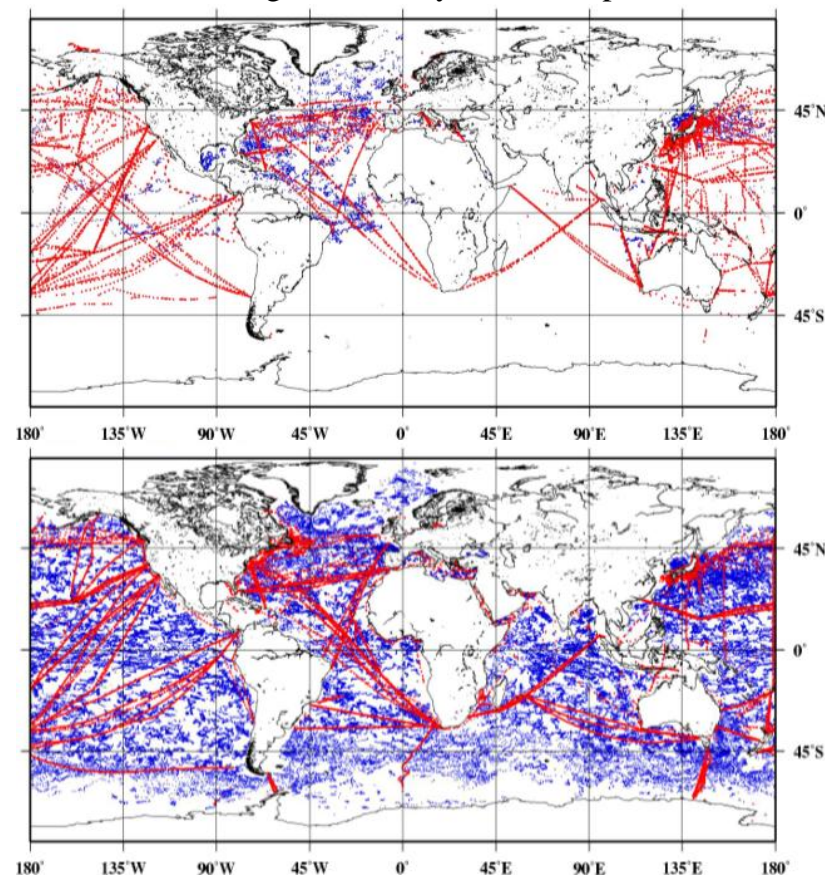

Figure 9. XBT (red) and Argo (blue) profile locations for the years 2000 (top) and 2007 (bottom) illustrate the evolution of both networks.

transects are one of the few sources of high resolution measurements in the boundary currents [20] and the only means of measuring time-varying geostrophic transport integrals from ocean boundary to ocean boundary. In addition to XBT sampling, many SOOP ships collect a range of other underway sea surface data, marine meteorology, and profile data [27].

Substantial issues for the XBT networks include the volatility of the shipping industry, making it difficult to maintain sampling along selected routes, and systematic measurement errors of temperature and depth (e.g. [26]). Systematic depth errors are thought to be due to small changes in manufacturing causing probe fall-rates to vary in time. Temperature errors can result from wire insulation problems, leading to an overall positive temperature bias because of the XBT's simple DC bridge circuitry that can be difficult to detect and estimate. Two technical developments are identified that could add substantial value to the XBT networks:

\subsubsection{Research-quality deep XBT}

A research-quality XBT, capable of 0-2000 m at 20 knot ship speed, with redesigned temperature circuitry and an electronic pressure-point for fall-rate calibration, is needed. Development of this instrument to the prototype stage was undertaken by Lockheed-Martin Sippican but is presently shelved. This instrument is needed to 
increase the accuracy and depth range relative to the conventional XBT. It would be especially valuable for sampling in the western boundary current regions, but would also have use in the ocean interior.

\subsubsection{Next-generation XBT automatic launcher}

XBT autolaunchers have been in use for 20 years and are valuable for automated control of high resolution sampling and for reducing XBT wire damage by shifting the deployment location from the bridge wings to the stern. However, installation can be timeconsuming, requiring a long cable run, and a technician ship-rider is usually needed for successful operation. Attributes of a next-generation autolauncher would include a self-contained unit at the stern (no cabling) to simplify installation, easier reloading by ship's crew, and improved bidirectional communication capabilities to allow near real-time data monitoring and control of deployments from shore.

\subsubsection{Data management}

In addition to these incremental technical developments, continuing improvements in data management will add further value to the SOOP XBT networks. The XBT community should consider and adopt homogenous quality control steps for all XBT observations, similar to those implemented by the Argo community. With the implementation of BUFR (Binary Universal Form for the Representation of meteorological data) format, realtime databases can include quality control flags. The determination and implementation of these flags, and the effort to create delayed-mode databases, should be coordinated within the scientific community. Metadata should be archived to enable delayed-mode quality control, and are central to addressing fall rate issues.

\subsection{VOS}

Marine meteorological and surface oceanographic measurements made by voluntary observers are coordinated by the JCOMM VOS scheme [38], and implemented by the national meteorological and hydrographic services that participate in VOS. These observations are assimilated into numerical weather prediction (NWP) models, and they form a research archive used for atmospheric reanalysis [41], climate research, and monitoring and assessment of air - sea interaction [4]. VOS data are freely available to the public, including via the International Comprehensive Ocean Atmosphere Data Set (ICOADS, [42] and [43]). ICOADS includes marine observations taken as early as 1662 , and for the past 50 years ships have reported all the variables (air temperature, humidity, wind speed and direction, SST (Sea Surface Temperature), SLP (Sea Level Pressure), and cloud information) required to estimate the surface turbulent and radiative fluxes, and with sufficient coverage to allow globally gridded fields to be calculated (e.g. [44] and [45]).

Unfortunately, the VOS fleet and its global coverage has declined over the past decade despite being the main provider of many of the Global Climate Observing System (GCOS, [46]) atmospheric essential climate variables (ECVs), including air temperature, humidity and surface pressure over the oceans. Contributing factors include less use of surface data in NWP relative to satellite data, reductions in the network of Port Meteorological Officers (PMOs) essential to recruit ships and maintain standards, and the previously mentioned volatility in shipping routes making it difficult to maintain sampling. These pressures, together with improving the data flow and meeting metadata requirements, are currently being tackled within JCOMM [38] and [43].

\subsubsection{System integration}

Despite the decline in global coverage and current pressures on the VOS fleet, the VOS data are still an essential component of the global ocean observing system to provide to long term observations of SST, air temperature and humidity, SLP, wind speed and direction. Estimates of wave, weather, and cloud parameters are also needed to extend long-term datasets [47], [44] and [48]. To ensure adequate data coverage of the different parameters requires observations from many ships, some with traditional observational methods to give broad coverage at 6-hourly intervals, and a subset with high quality instrumentation making more frequent observations. The strengthening of emerging links between VOS and the Shipboard Automated Meteorological and Oceanographic Systems (SAMOS) initiative would enable research vessels to contribute more effectively to the VOS program, and allow the VOS to take advantage of the sophisticated measurement and quality assurance systems developed by SAMOS. Many VOS are already equipped with automatic systems and VOS and SAMOS share common goals including the wide provision of high quality, consistent data to the research community. SAMOS-equipped research vessels also contribute data in many regions that are not visited by commercial shipping.

\subsubsection{Need for defined sampling requirements}

Although the VOS are an important and continuing component of GCOS, the requirements for VOS are not well defined. This is in part due to the separate treatment of the atmospheric and marine components of the GCOS implementation plan [46], resulting in welldefined metrics and requirements for the marine component but less well-defined metrics and requirements for the atmospheric component over the oceans. Improving the definition of the user 
requirements for the atmospheric ECVs over the oceans and the metrics by which the completeness of the atmospheric observing system is measured are essential to define the data requirements for the VOS scheme (and the wider in situ observing system) and to properly integrate the observations in GCOS. Presently the shape of the VOS fleet, and hence the contribution of VOS to GCOS, is set by the priorities of the national meteorological and hydrographic services who fund the data collection rather than by requirements for climate research and monitoring. However defining metrics for the surface meteorological observing system will require research including improved estimates of variability over the ocean.

\section{AUTOMATED UNDERWAY OBSERVATIONS}

Alongside the 6-hourly sampling of basic weather variables from VOS, the past decade has seen the rapid expansion of high-temporal ( $<1 \mathrm{~min}$. interval samples) automated observations on some commercial and research vessels [49]. These sophisticated suites of meteorological and oceanographic instrumentation provide a detailed picture of conditions at the air-sea interface. Atmospheric measurements include winds, humidity, air temperature, pressure, and precipitation. Common atmospheric radiation measurements include total solar (shortwave) and downwelling longwave (from clouds and sky). Occasionally vessels deploy net, ultraviolet, and photosynthetically active radiometers. Ocean measurements from continuous water sampling systems include sea surface temperature, salinity, and in some cases florescence and dissolved oxygen. Additional underway measurements include atmospheric and oceanic $\mathrm{pCO}_{2}$, direct fluxes, radiative SST, currents (e.g., from an Acoustic Doppler Current Profiler, ADCP), and bathymetry.
Automated sampling of meteorological and ocean surface variables is both a challenge and great opportunity for the coming decade. It provides a host of benefits to both the operator and the data collector, but also poses challenges for differentiating automated and manual observations. Automated observing systems can collect a wide range of ocean and atmospheric parameters desired by the satellite observing and ocean/atmosphere modeling communities, for example radiation, currents, and $\mathrm{pCO} 2$. The coming decade will include a continued move towards automation of underway measurements on ships participating in VOS, SOOP, or select research operations (e.g., repeat hydrography).

The key for the next decade is to improve the stewardship of automated underway observations to make them available for integration into models or for use for validation or algorithm development in the satellite and air-sea flux communities. Ongoing national efforts to collect all underway observations from ships(not just those from repeat hydrographic research cruises) should be continued and expanded. Examples include the SAMOS initiative [50] and the Rolling Deck to Repository Project in the U.S., the Australian Integrated Marine Observing System, the French led Global Ocean Surface Underway Data project, and a developing program in Germany to collect underway data from their ocean class research vessels.

Expanding interactions and partnerships between existing programs is also needed. The SOOP program is beginning to consider its role in the collection of data from ADCP, thermosalinograph, and other underway water-sampling systems. As more VOS begin using automated weather systems, the opportunity exists to

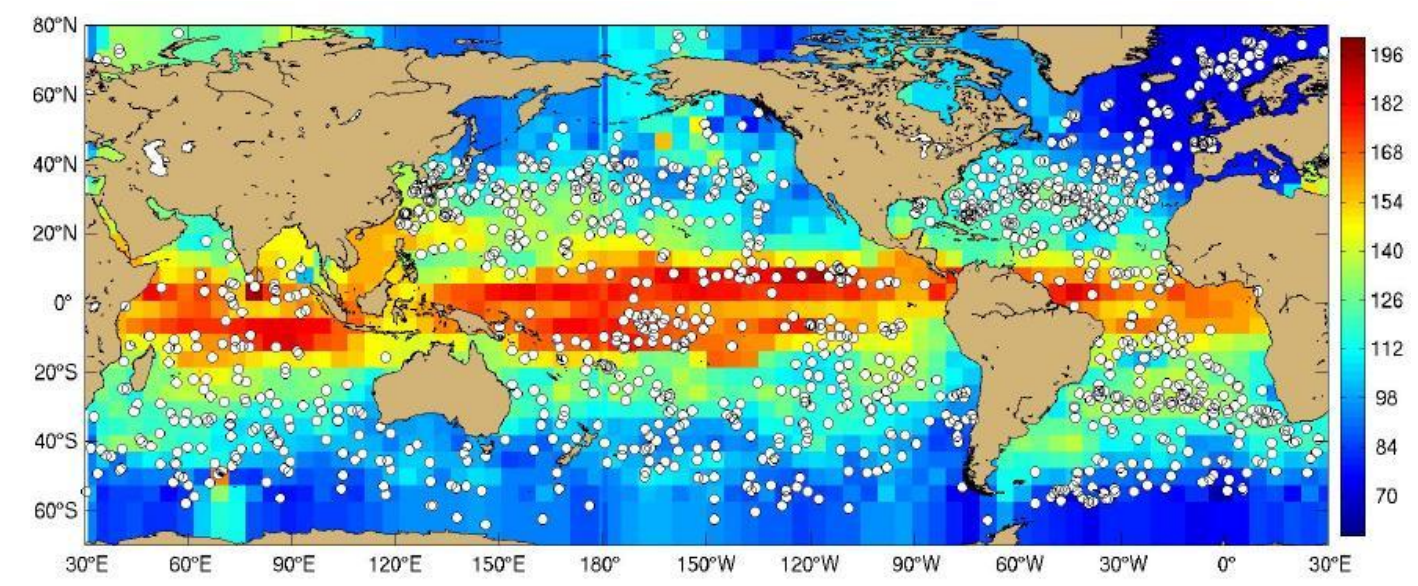

Figure 10. Present surface drifter locations (circles) and altimetry-derived eddy length scales (shading, $\mathrm{km}$ ) [53].

collect high-temporal samples $(<1$ min interval) desired by the research and satellite communities using the same AWS (Automatic Weather Station) to support the goals of numerical weather forecasting centers. Further 
connections with the global carbon and radiation programs (e.g., Baseline Surface Radiation Network) will aid the development of integrated global products necessary to further our understanding of the ocean climate system.

\section{THE DRIFTER NETWORK}

The design of the Global Drifter Program, to include 1250 surface drifters at $5^{\circ} \times 5^{\circ}$ spacing, was based on a primary objective of calibrating satellite SST measurements [51]. However, in the sustained ocean observing system for climate there is also a compelling need for observations of the ocean surface layer circulation (Fig. 10) to understand its roles in advection of heat and other properties. A global ocean surface velocity product is estimated from satellite sea surface height, sea surface temperature, and wind stress (Ocean Surface Current Analysis Real-time, OSCAR, [52]). While this product is validated with near-surface velocity measurements from drifters and moorings, there is nonetheless a need for improved measurements of surface velocity. It is widely agreed that the present $5^{\circ} \times 5^{\circ}$ measurement resolution of the surface velocity field is not adequate.

Requirements for surface drifters are presently being reviewed [54] for their adequacy to define the mean circulation [55] and the seasonal to inter-annual variability, for calibration of satellite-derived sea surface velocity, for their ability to resolve eddy kinetic energy and coastal processes, and for deploying ancillary sensors for SLP, SSS and PCO2.

\section{1 .CONCLUSIONS}

The top priority for the coming decade must be to sustain the present ocean observing system, while improving its coverage and data quality. The system also can be significantly enhanced by the following extensions of existing elements and by integration across elements:

- The sampling domain of autonomous platforms can become truly global through extensions to higher latitude, into marginal seas and the deep ocean, and through higher resolution observations in boundary current regions. Incremental technology developments and definition of new sampling requirements are needed for these extensions. A modest amount of dedicated (small) RV support is an essential adjunct for the autonomous networks.

- The global network measuring the physical state of the oceans provides a platform for multidisciplinary observations of biogeochemical and ecosystem impacts of climate change. Key requirements are further developments in lowpower sensor accuracy and stability, and effective integration between autonomous and shipboard observational networks (e.g. definition of core variables; ensuring a sufficient quantity of reference-quality data for quality assurance of autonomous sensors).

- Improvements in the observation of the ocean surface layer and of air-sea exchanges require better utilization of research vessels and commercial shipping, improvements to automated measurement systems, better coordination across networks, and a review of sampling requirements for marine meteorology and ocean surface velocity.

- A major effort is needed to ensure that data quality is maximized, that data access is simplified (including for data types extending across multiple observational networks), and that data products are useful and available.

Though the focus here has been on mobile platforms, we recognize the complementary relationship between these and the fixed in situ platforms and satellite systems (e.g. Sect. 2) that are the subject of other OceanObs'09 studies. A common theme must be to set priorities for action in each observing system element according to the benefits to the total integrated observing system. Autonomous mobile platforms occupy a central position since it is these instruments that have brought about the revolution in subsurface ocean observations in the last 10 years, paralleling the earlier role of satellites in making global observations for the ocean surface. In the next 10 years, autonomous networks must be further developed and implemented until they realize their value as mature systems. This will make high demands on the human resources of the ocean observation community and will require new levels of coordination and consensus to redirect the community's collaborative effort toward truly global objectives.

Finally, for efficient evolution of the observing system, a strategy is needed for reviewing the status of all components on a regular basis and their adequacy in meeting user requirements. There are two parts to such a process. First, each observing system element has (or should have) an international implementation panel, and the terms of reference for these panels should include interactions with identified user communities. Observing system adequacy is application-specific, so the major users play critical roles in evaluating the spatial and temporal coverage of sampling and the data quality and timeliness in the context of their application. We believe that these interactions between implementation groups and users are occurring in most cases and should be further encouraged. Appropriate venues include regular meetings and workshops held by the implementation panels and by user groups such as 
GODAE (Global Ocean Data Assimilation Experiment), OceanView and CLIVAR. The implementation panels and user groups have some cross-representation for this function. The second, more challenging part of the process is evaluation of the system as a whole, including its synergistic relationships. The OceanObs process provides a crucial framework for this evaluation, bringing together at decadal intervals the communities of observing system implementers, sponsors, and users. OceanObs'09 incorporates valuable assessments [e.g. 56] of the present observing system in the context of synthesis and assimilation systems, and provides recommendations for sustaining and evolving it. Another outcome of the decadal review is an update of user requirements for observational networks based on new information, new capabilities, and on the evolution of complementary networks. The OceanObs decadal reviews have been carried out under the guidance of the Ocean Observations Panel for Climate (OOPC) and the CLIVAR Global Synthesis and Observations Panel, both of which have identified functions similar to "help develop a process for ongoing evaluation and evolution of the observing system". On a more frequent basis, conferences such as the International Association for the Physical Science of the Ocean (IAPSO) provide valuable forums for community-wide dialog. A recommendation is to regularize the decadal review process of OceanObs under OOPC, and to formalize more frequent and targeted evaluations of observing system adequacy utilizing IAPSO or other appropriate forums.

\section{REFERENCES}

1. Guinehut, S., P. Le Traon, \& G. Larnicol (2006). What can we learn from global altimetry/hydrography comparisons? Geophys. Res. Lett. 33, L10604, doi:10.1029/2005GL025551.

2. Willis, J. K., \& L.-L. Fu (2008). Combining altimeter and subsurface float data to estimate the time-averaged circulation in the upper ocean, J. Geophys. Res., 113, C12017, doi:10.1029/2007JC004690.

3. Leuliette, E. W., \& L. Miller (2009). Closing the sea level rise budget with altimetry, Argo, and GRACE, Geophys. Res. Lett., 36, L04608, doi:10.1029/2008GL036010.

4. Fairall, C. \& Co-Authors (2010). "Observations to Quantify Air-Sea Fluxes and their Role in Climate Variability and Predictability" in these proceedings (Vol. 2), doi:10.5270/OceanObs09.cwp.27.

5. Belbeoch, M. \& Co-Authors (2010). "The JCOMM In Situ Observing Platform Support Centre: A Decade of Progress and Remaining Challenges" in these proceedings (Vol. 2), doi:10.5270/OceanObs09.cwp.04.

6. Hankin, S. \& Co-Authors (2010). "NetCDF-CF-OPeNDAP: Standards for Ocean Data Interoperability and Object Lessons for Community Data Standards Processes" in these proceedings ( $\mathrm{Vol} .2$ ) doi:10.5270/OceanObs09.cwp.41.

7. Freeland, H. \& Co-Authors (2010)."Argo - A Decade of Progress" in these proceedings (Vol. 2), doi:10.5270/OceanObs09.cwp.32.

8. Klatt, O., O. Boebel, \& E. Fahrbach, (2007). A profiling float's sense of ice. Journal of Atmospheric and Oceanic Technology, 24, 1301-1308.

9. Van Wijk, E. and Co-Authors (2010). "Observing High Latitudes: Extending the Core Argo Array" in these proceedings (Annex).

10. Lee, C. \& Co-Authors (2010). "Autonomous Platforms in the Arctic Observing Network" in these proceedings (Vol. 2), doi:10.5270/OceanObs09.cwp.54.

11. Rintoul, S. \& Co-Authors (2010). "Southern Ocean Observing System (SOOS): Rationale and Strategy for Sustained Observations of the Southern Ocean" in these proceedings (Vol. 2), doi:10.5270/OceanObs09.cwp.74.

12. Garzoli, S. \& Co-Authors (2010). "Progressing Towards Global Sustained Deep Ocean Observations" in these proceedings (Vol. 2), doi:10.5270/OceanObs09.cwp.34.

13. Cronin, M. \& Co-Authors (2010). "Monitoring Ocean Atmosphere Interactions in Western Boundary Current Extensions" in these proceedings (Vol. 2), doi:10.5270/OceanObs09.cwp.20.

14. Gruber, N. \& Co-Authors (2010). "Adding Oxygen to Argo: Developing a Global In Situ Observatory for Ocean Deoxygenation and Biogeochemistry" in these proceedings (Vol. 2), doi:10.5270/OceanObs09.cwp.39.

15. Riser, S.C., \& K.S. Johnson (2008). Net production of oxygen in the subtropical ocean. Nature 451, 323-326, doi:10.1038/nature06441.

16. Claustre, H. \& Co-Authors (2010). "Bio-Optical Profiling Floats as New Observational Tools for Biogeochemical and Ecosystem Studies: Potential Synergies with Ocean Color Remote Sensing." in these proceedings (Vol. 2), doi:10.5270/OceanObs09.cwp.17.

17. MacKinnon, J. \& Co-Authors (2010). "Using Global Arrays to Investigate Internal-Waves and Mixing" in these proceedings (Vol. 2), doi:10.5270/OceanObs09.cwp.58.

18. Testor, P. \& Co-Authors (2010). "Gliders as a Component of Future Observing Systems" in these proceedings (Vol. 2), doi:10.5270/OceanObs09.cwp.89.

19. Imawaki, S., W. Zenk, S. Wijffels, D. Roemmich \& M. Kawabe (2001). Oceanic boundary currents. Observing the Oceans in the $21^{\text {st }}$ Century, C. Koblinksy and N. Smith (eds), Bureau of Meteorology, Melbourne Australia, 2001.

20. Send, U. \& Co-Authors (2010). "A Global Boundary Current Circulation Observing Network" in these proceedings (Vol. 2), doi:10.5270/OceanObs09.cwp.78.

21. Roemmich, D., J. Gilson, B. Cornuelle \& R. Weller, (2001). The mean and time-varying meridional heat 
transport at the tropical/subtropical boundary of the North Pacific Ocean. J. Geophys. Res., 106, 8957-8970.

22. Douglass, E.M., D. Roemmich \& D. Stammer (2009). Interannual variability in North Pacific heat and freshwater budgets. Deep-Sea Res., in press.

23. Hood, M. \& Co-Authors (2010). "Ship-Based Repeat Hydrography: A Strategy for a Sustained Global Program." in these proceedings (Vol. 2), doi:10.5270/OceanObs09.cwp.44.

24. Wong, A. P. S. \& W.B. Owens (2009). An improved calibration method for the drift of the conductivity sensor on autonomous CTD profiling floats by $\Theta-S$ climatology, Deep-Sea Res. I, 56, 450-457, doi:10.1016/j.dsr.2008.09.008.

25. Willis, J.K., J. M. Lyman, G. C. Johnson, \& J. Gilson (2008). In situ data biases and recent ocean heat content variability. J. Atmos.Oceanic Technol., 26, 846-852.

26. Wijffels, S. E., J. Willis, C. M. Domingues, P. Barker, N. J. White, A. Gronell, K. Ridgway, \& J. A. Church (2008). Changing eXpendable BathyThermograph fall rates and their impact on estimates of thermosteric sea level rise. J. Climate, 21, 5657-5672.

27. Goni, G. \& Co-Authors (2010). "The Ship of Opportunity Program" in these proceedings (Vol. 2), doi:10.5270/OceanObs09.cwp.35.

28. Boehlert, G.W., D.P. Costa, D.E. Crocker, P. Green, T. O'Brien, S. Levitus, \& B.J. Le Boeuf, (2001). Autonomous Pinniped Environmental Samplers: Using Instrumented Animals as Oceanographic Data Collectors. J. Atmos. Oceanic Technol., 18, 1882-1893.

29. Boehme, L. \& Co-Authors (2010). "Biologging in the Global Ocean Observing System" in these proceedings (Vol. 2), doi:10.5270/OceanObs09.cwp.06.

30. Nicholls, K.W., L. Boehme, M. Biuw, \& M.A. Fedak (2008). Wintertime ocean conditions over the southern Weddell Sea continental shelf, Antarctica., Geophys. Res. Lett., 35, L21605, doi:10.1029/2008GL035742.

31. Charrassin J.-B. \& 21 co-authors (2008). Southern Ocean frontal structure and sea ice formation rates revealed by elephant seals. Proceedings of the National Academy of Sciences 105, 11634-11639

32. Costa, D.P., J. Klinck, E.E. Hofmann, M. Dinniman, J.M. Burns (2008). Upper ocean variability in west Antarctic Peninsula continental shelf waters as measured using instrumented seals, Deep-Sea Research II, 55, 323-337.

33. Meredith, M.P., K.W. Nicholls, I.A. Renfrew, L. Boehme, M. Biuw, M. Fedak (2009). Seasonal evolution of the upper-ocean adjacent to the South Orkney Islands, Southern Ocean: results from a "lazy biological mooring", Deep Sea Research II, accepted.

34. Boehme, L., M.P. Meredith, S.E. Thorpe, M. Biuw, M. Fedak (2008). Antarctic Circumpolar Current frontal system in the South Atlantic: Monitoring using merged Argo and animal-borne sensor data. J. Geophys. Res., 113, C09012, doi:10.1029/2007JC004647.
35. Boehme, L., S.E. Thorpe, M. Biuw, M. Fedak, M.P. Meredith (2008). Monitoring Drake Passage with elephant seals: Frontal structures and snapshots of transport., Limnology \& Oceanography, 53, 2350-2360.

36. Boehme, L., P. Lovell, M. Biuw, F. Roquet, J. Nicholson, S. E. Thorpe, M. P. Meredith, \& M. Fedak (2009), Technical Note: Animal-borne CTD-Satellite Relay Data Loggers for real-time oceanographic data collection., Ocean Sci. Discuss., 6, accepted.

37. Charrassin, J. \& Co-Authors (2010). "New Insights into Southern Ocean Physical and Biological Processes Revealed by Instrumented Elephant Seals" in these proceedings (Vol. 2), doi:10.5270/OceanObs09.cwp.15.

38. Kent, E. \& Co-Authors (2010). "The Voluntary Observing Ship (VOS) Scheme" in these proceedings (Vol. 2), doi:10.5270/OceanObs09.cwp.48.

39. Levitus, S., J. I. Antonov, T. P. Boyer, R. A. Locarnini, H. E. Garcia, \& A. V. Mishonov (2009). Global ocean heat content 1955-2008 in light of recently revealed instrumentation problems, Geophys. Res. Lett., 36, L07608, doi:10.1029/2008GL037155.

40. Smith, N., R. Bailey, O. Alves, T. Delcroix, K. Hanawa, E. Harrison, R. Keeley, G. Meyers, R. Molinari, \& D. Roemmich (2001). The upper ocean thermal network. Observing the Oceans in the $21^{\text {st }}$ Century, C. Koblinksy and N. Smith (eds), Bureau of Meteorology, Melbourne Australia, 2001

41. Trenberth, K. \& Co-Authors (2010). "Atmospheric Reanalyses: A Major Resource for Ocean Product Development and Modeling" in these proceedings (Vol. 2), doi:10.5270/OceanObs09.cwp.90.

42. Worley SJ, Woodruff SD, Reynolds RW, Lubker SJ, Lott N (2005). ICOADS Release 2.1 data and products. Int. J. Climatol. 25, 823-842.

43. Woodruff, S. \& Co-Authors (2010). "Surface In Situ Datasets for Marine Climatological Applications" in these proceedings (Vol. 2) doi:10.5270/OceanObs09.cwp.93.

44. Da Silva, A., C.C. Young, \& S. Levitus (1994). Atlas of Surface Marine Data 1994 Vol. I: Algorithms and Procedures. NOAA Atlas NESDIS 6, U.S. Dept. Of Commerce, Washington, D.C., 83 pp.

45. Berry, D.I., \& E.C. Kent (2009). A new air-sea interaction gridded dataset from ICOADS with uncertainty estimates. Bull. Amer. Meteor. Soc., 90, 645-656. doi:10.1175/2008BAMS2639.1

46. GCOS (2004). Implementation Plan for the Globa Observing System for Climate in support of the UNFCCC (GCOS-92), the Global Climate Observing System, October 2004, GCOS No. 92, WMO/TD No. 1219.

47. Gulev, S.K., V. Grigorieva (2006). Variability of the winter wind waves and swell in the North Atlantic and North Pacific as revealed by the Voluntary Observing Ship data. J. Climate, 19, 5667-5785. 
48. Hahn, C.J., \& S.G. Warren (1999). Extended Edited Cloud Reports from Ships and Land Stations over the Globe, 1952-1996. Numerical Data package NDP-026C, Carbon Dioxide Information Analysis Center (CDIAC), Department of Energy, Oak Ridge, Tennessee (Documentation, 79 pages).

49. Smith, S. \& Co-Authors (2010). "Automated Underway Oceanic and Atmospheric Measurements from Ships" in these proceedings (Vol. 2), doi:10.5270/OceanObs09.cwp.82.

50. Smith, S. \& Co-Authors (2010). "The Data Management System for the Shipboard Automated Meteorological and Oceanographic System (SAMOS) Initiative" in these proceedings (Vol. 2), doi:10.5270/OceanObs09.cwp.83.

51. Zhang, H.M., R.W. Reynolds, R. Lumpkin, R. Molinari, K. Arzayus, M. Johnson, \& T.M. Smith, (2009). An Integrated Global Observing System For Sea Surface Temperature Using Satellites and in Situ Data: Research to Operations. Bull. Amer. Meteor. Soc., 90, 31-38.

52. Bonjean, F., \& G.S.E. Lagerloef, (2002). Diagnostic Model and Analysis of the Surface Currents in the Tropical Pacific Ocean. J. Phys. Oceanogr., 32, 29382954.

53. Stammer D. (1997). Global characteristics of ocean variability estimated from regional TOPEX/Poseidon altimeter measurements. J. Phys. Oceanogr., 27, 17431769.

54. Dohan, K. \& Co-Authors (2010). "Measuring the Global Ocean Surface Circulation with Satellite and In Situ Observations" in these proceedings (Vol. 2), doi:10.5270/OceanObs09.cwp.23.

55. Maximenko, Nikolai, Peter Niiler, Luca Centurioni, MarieHelene Rio, Oleg Melnichenko, Don Chambers, Victor Zlotnicki, Boris Galperin, 2009: Mean Dynamic Topography of the Ocean Derived from Satellite and Drifting Buoy Data Using Three Different Techniques*. J. Atmos. Oceanic Technol., 26, 1910-1919. doi:10.1175/2009JTECHO672.1.

56. Rienecker, M. \& Co-Authors (2010). "Synthesis and Assimilation Systems - Essential Adjuncts to the Global Ocean Observing System" in these proceedings (Vol. 1), doi:10.5270/OceanObs09.pp.31. 